Grand Valley State University

ScholarWorks@GVSU

\title{
An Examination of the Interactions of Race and Gender on Sentencing Decisions Using a Trichotomous Dependent Variable
}

Tina L. Freiburger

University of Wisconsin - Milwaukee, freiburg@uwm.edu

Carly M. Hilinski-Rosick

Grand Valley State University, hilinskc@gvsu.edu

Follow this and additional works at: https://scholarworks.gvsu.edu/scjpeerpubs

Part of the Criminology and Criminal Justice Commons

\section{ScholarWorks Citation}

Freiburger, Tina L. and Hilinski-Rosick, Carly M., "An Examination of the Interactions of Race and Gender on Sentencing Decisions Using a Trichotomous Dependent Variable" (2013). Peer Reviewed Publications. 12.

https://scholarworks.gvsu.edu/scjpeerpubs/12

This Article is brought to you for free and open access by the School of Criminology, Criminal Justice, and Legal Studies at ScholarWorks@GVSU. It has been accepted for inclusion in Peer Reviewed Publications by an authorized administrator of ScholarWorks@GVSU. For more information, please contact scholarworks@gvsu.edu. 
An Examination of the Interactions of Race and

Gender on Sentencing

Decisions Using a

Trichotomous

Dependent Variable
(C) The Author(s) 2013

Reprints and permission: sagepub.com/journalsPermissions.nav DOI: I0.1 I77/00 I I I28708330178 http://cad.sagepub.com

(3)AGE

\title{
Tina L. Freiburger' and Carly M. Hilinski ${ }^{2}$
}

\begin{abstract}
This study examined how race, gender, and age interact to affect defendants' sentences using a trichotomized dependent variable. The findings indicate that the racial and gender disparity found in sentencing decisions was largely due to Black men's increased likelihood of receiving jail as opposed to probation. The results also show that being young resulted in increased odds of receiving probation over jail for White men and for women but resulted in decreased odds for Black men. Separate analysis of incarceration terms to jail and prison further reveal that legal factors had a greater impact on prison than on jail sentence length. Overall, the results strongly support the argument that sentencing research needs to consider sentences to jail and prison separately.
\end{abstract}

\section{Keywords}

sentencing, disparity, race and gender bias

\footnotetext{
'University of Wisconsin-Milwaukee

${ }^{2}$ Grand Valley State University, Grand Rapids, Michigan

Corresponding Author:

Tina L. Freiburger, University of Wisconsin-Milwaukee, Department of Criminal Justice, P.O.

Box 786, I I39 Enderis Hall, Milwaukee,WI 5320I

Email: freiburg@uwm.edu.
} 
Concern over possible bias in the court system has prompted a large body of research inquiring into disparities across the sentencing of various groups. Attention has been especially prominent in the area of racial and gender bias. Although many earlier studies limited their examinations to one of these areas, several current studies have inquired into their interaction effects (e.g., Bickle \& Peterson, 1991; Spohn \& Beichner, 2000; Spohn, Welch, \& Gruhl, 1985; Steffensmeier \& Demuth, 2006). Other studies have furthered inquiry to examine how age may interact with race and gender (e.g., Steffensmeier, Ulmer, \& Kramer, 1998). This research has allowed for a better understanding of the experiences of unique groups within the judicial system.

Although research into the interaction of race, gender, and age has succeeded in offering a more comprehensive picture of these groups' experiences, it has produced inconsistent results. Some studies have found that minority women do not receive the type of leniency that is granted to White women (e.g., Crawford, 2000; Steffensmeier et al., 1998). Conversely, other studies have found that minority women are actually sentenced more leniently than White women are (e.g., Spohn \& Beichner, 2000; Steffensmeier $\&$ Demuth, 2006). When interactions for age, race, and gender are considered, it appears that age has a greater influence on Black male defendants, with young Black men receiving the harshest treatment (e.g., Steffensmeier et al., 1998). Questions remain with respect to the treatment of different offenders by the court, making further inquiry necessary.

Recent work by Spohn and colleagues (Harrington \& Spohn, 2007; Holleran \& Spohn, 2004) has made an important contribution to the understanding of sentencing decisions and to the experiences of these groups. Their research has found that race and gender may affect only certain incarceration decisions (i.e., jail vs. prison) and, further, may affect those decisions differently. Their work challenges the commonly used in/out measure, arguing that jail and prison are "qualitatively different" (Holleran \& Spohn, 2004). Their findings (Harrington \& Spohn, 2007; Holleran \& Spohn, 2004) strongly support this assertion and offer compelling evidence to suggest that differential treatment of various groups cannot be fully understood until this distinction is made in quantitative research. Other than Harrington and Spohn's study, past research examining the interaction of race and gender has utilized a dichotomized in/out dependent variable and has not distinguished between a sentence of jail or prison. Previous research also has failed to examine the length of the sentence term to jail and prison separately to determine if different factors are considered by judges in deciding the length of a jail term versus a prison term. 


\section{Prior Research}

\section{Gender and Sentencing Decisions}

A great deal of research has been conducted to determine whether gender disparities exist in sentencing decisions (for reviews of the literature, see Daly \& Bordt, 1995; Spohn \& Beichner, 2000; Steffensmeier, Kramer, \& Streifel, 1993). The majority of these studies have found that gender disparity does exist in the decision to incarcerate a defendant in either prison or jail (often referred to as the in/out decision). These findings indicate that this disparity appears to benefit women, with men significantly more likely than women to be sentenced to a term of incarceration (Spohn \& Beichner, 2000; Spohn \& Holleran, 2000; Steffensmeier et al., 1993; Steffensmeier et al., 1998).

Unlike research on the sentence severity decision, the research examining the influence of gender on sentence length is mixed and contradictory. Many studies have found that women receive shorter sentences than men do (Albonetti, 1997; Bushway \& Piehl, 2001; Farnworth \& Teske, 1995; Huang, Finn, Ruback, \& Friedmann, 1996; Jeffries Fletcher, \& Newbold, 2003; Mustard, 2001; Orsagh, 1985; Rodriguez, Curry, \& Lee, 2006; Ulmer \& Kramer, 1996). Several studies, however, have failed to find differences between the sentence lengths of men and of women (Crew, 1991; Nobiling, Spohn, \& DeLone, 1998; Steffensmeier et al., 1993). Additional studies have even indicated that women receive longer sentences than men do. Myers (2001) found that women received significantly longer sentences than men do for violent, property, and white-collar offenses. Steffensmeier's et al. (1993) analysis of 61,294 cases in Pennsylvania also found gender to have only a very small negative effect, with men receiving slightly lesser sentences than women do (1.6 months).

Overall, the research on sentence length indicates that women receive shorter sentences than men do; however, the effect seems to be less consistent than in the incarceration decision (Daly \& Bordt, 1995). This finding of leniency for women has been linked to many explanations. Although earlier explanations were dominated by the chivalry thesis, which suggested that judges had a desire to protect the "weaker sex" from severe punishments, more recent explanations have focused on women's role in society. These explanations point to perceptions of women as being less dangerous and to the higher social costs associated with women's incarceration (see Daly, 1987; Steffensmeier et al., 1998) to justify their more lenient treatment in the courtroom.

\section{Race and Sentencing Decisions}

In addition to the research on gender effects, many studies have examined the relationship between race and sentencing. In a review of literature 
examining sentencing disparities between White and Black defendants, Chiricos and Crawford (1995; also see Zatz, 2000) concluded that Black defendants were more likely than White defendants to be incarcerated, when relevant variables were controlled. In addition, recent research continues to find that Whites are treated with greater leniency than Blacks at various stages of the judicial process, after stringent controls are utilized for relevant variables (Kramer \& Steffensmeier, 1993; Rodriguez et al., 2006; Spohn \& Beichner, 2000). The research examining sentence length, however, has been less consistent. Several studies have found that race is not a significant predictor of sentence length (Demuth \& Steffensmeier, 2004; Kramer \& Steffensmeier, 1993) or that the effect is small or negligible (Spohn \& Holleran, 2000; Steffensmeier et al., 1998; Steffensmeier \& Demuth, 2000).

\section{Race, Gender, and Age Interactions}

Recent studies have found that women, regardless of race, are sentenced more leniently than their male counterparts. In addition, race has been found to have a larger effect on the sentences of men than on the sentences of women, with Black men being sentenced more harshly than White men (Albonetti, 1997; Steffensmeier \& Demuth, 2006; Steffensmeier et al., 1998). When Steffensmeier and colleagues (1998) considered the interaction of race, gender, and age, they found that racial disparity was largest among young men, with young Black men being sentenced harsher than any other group. They concluded that these findings were due to young Black men being viewed by the court as more blameworthy and dangerous. In addition, young Black men were viewed as better able to "do time" and less amenable to rehabilitation. Furthermore, the only incidence where female defendants did not receive leniency over male defendants was when the sentences of young women (under 30) were compared to those of older males (over 50).

When comparisons are made of White and Black women, however, the results are less clear. Some researchers have found that, like Black men, Black women receive harsher sentences than their White counterparts do (Crawford, 2000; Moulds, 1980; Steffensmeier et al., 1998). Brennan (2006) found that race indirectly affected women's sentences through such variables as offense severity, prior record, community ties, and social-economic status, with Black and Hispanic women being more likely than White women to receive jail sentence. Conversely, a body of research exists that has found the opposite and has indicated that Black women actually receive the most preferential treatment (Bickle \& Peterson, 1991; Spohn \& Beichner, 2000; Steffensmeier \& Demuth, 2006). Spohn and Beichner found that both Black women and White women were significantly less likely to receive a 
sentence of incarceration than both Black men and White men in Kansas City and Chicago. Analysis in Miami, however, showed that Black women were significantly less likely than Black men to be sentenced to incarceration, but White women, compared to White men, did not receive this preferential treatment.

When age was considered, young Black and Hispanic defendants had higher odds of being sentenced to prison in all three jurisdictions. As suggested by these findings, examinations of race and gender disparities in sentencing decisions might not provide an accurate understanding of judicial decisions, and it cannot be assumed that all men, women, Blacks, and Whites have the same experiences in the courtroom. The current research suggests that race and gender actually interact and that different race-gender combinations have different effects on sentence outcomes. Further analysis considering age indicates that the age of the defendant also may have an influence on shaping judges' perceptions.

\section{Operationalization of Dependent Variables}

Steffensmeier et al.'s (1993) examination of the effects of gender on sentencing found that leniency toward women depended on the operationalization of the dependent variable. Their analysis examined three different forms of the in/out decision. The first analysis operationalized "in" as a sentence to either jail or state incarceration in prison and "out" as any other sentence that did not include confinement. Using this operationalization, they found that men had a $12 \%$ greater chance of being incarcerated than women did. The second analysis defined "in" as a sentence to state prison and "out" as any other sentence, which included jail. This analysis also found that men were more likely than women to receive the "in" sentence. The last operationalization classified "in" as incarceration in state prison and "out" as jail (therefore, both were actually incarcerative sentences). When the in/out decision was restricted to this operationalization, men and women had an almost equal chance of receiving the "in" sentence of incarceration to a state facility. These results indicated that the operationalization of the in/out decision may affect the findings.

More recent work by Holleran and Spohn (2004) and Harrington and Spohn (2007) has further questioned the use of a dichotomous dependent variable that only distinguishes between sentences of incarceration and probation. Research conducted by Holleran and Spohn examined defendants sentenced in Philadelphia, Pennsylvania, in 1998 to determine whether different operationalizations of the in/out decision affected disparity interpretations. Similar to Steffensmeier's et al. (1993) findings, they found that when the 
dichotomized in/out measure was used, minorities (Hispanics and Blacks) and men were sentenced more harshly than Whites and women. When separate models were analyzed for jail and prison, however, they found that gender was no longer a significant predictor. These results were further supported with the authors' analysis of a multinomial logistic regression model that indicated that different variables had different effects on the decision to sentence a defendant to jail than on the decision to sentence a defendant to prison. Women were significantly more likely than men to receive probation over jail and probation over prison. White defendants were more likely than Hispanic defendants to receive probation over jail and probation over prison; Black defendants, however, were more likely than Hispanics to receive jail but not more likely to receive probation as opposed to prison.

Harrington and Spohn (2007) replicated the previous study using 2001 court data from a Midwest county. The results of this study offered further support for the assertion that jail and prison are qualitatively different and that quantitative analyses need to recognize these differences to develop an accurate understanding of sentencing decisions. Their results suggested that when a dichotomized in/out variable was used, White defendants and female defendants were significantly less likely to be incarcerated than Black defendants and men were. Examination of the multinomial model indicated, however, that women only received leniency in the sentencing decision between probation and jail but not in the decision between jail and prison. The effect of race also was altered, with Black defendants having a greater likelihood of being sentenced to jail over probation but being less likely than White defendants to be sentenced to prison over jail. Additional examination of interaction effects found that Black men were more likely than any other group to be sentenced to jail over probation, whereas White men had greater odds than any other group of being incarcerated in prison rather than in jail.

Inconsistency in the research with respect to the interaction of race and gender indicates a need for further inquiry into how these relationships intersect. Furthermore, important contributions by Holleran and Spohn (2004) and Harrington and Spohn (2007) have called many of the previous findings in this area into question. This study attempts to further the understanding of how race and gender interact to affect the sentencing decisions of judges. It also contributes to the earlier work of Holleran and Spohn (2004) and of Harrington and Spohn (2007) by employing a trichotomous dependent variable. In addition, existing research will be expanded by considering jail and prison sentence length separately. The present study, therefore, explores the possibility that different factors are considered by judges when sentencing a defendant to jail or to prison. 


\section{Method}

The present study examined the effects of race, gender, and age on the sentencing decisions of felony offenders in an urban county in Michigan. ${ }^{1}$ The data analyzed contain information collected from presentence investigation reports completed for all offenders convicted of a personal, drug, or property offense and sentenced in the county during 2006. The original data set contained 3,223 cases. Due to the small number of Hispanic defendants and defendants of other ethnicities $(n=73)$, a meaningful analysis for these groups was not possible; therefore, they were removed from the data set. Cases in which the defendant was sentenced to a split sentence or a sentence simply classified as "other" $(n=531)$ were also excluded from the data set. Other cases $(n=608)$ were missing pertinent information regarding the offense severity level and prior record level, and they were also removed from the data set because of the importance of including these variables in sentencing research. Therefore, the final data set contained 2,011 cases.

Significance tests performed to determine if any differences existed between the cases excluded due to missing data and the cases included in the final data set reveal that there were some significant differences between the two groups. ${ }^{2}$ Among the independent variables of interest, neither race, age, nor gender was significantly different across the two groups, although the differences for the two groups across age approached significance. Among the other independent variables, cases excluded from the data set due to missing information were more likely to be released prior to trial and more likely to be convicted by a jury. Among the dependent variables, cases excluded were less likely to receive a probation or prison sentence but more likely to receive a jail sentence. Excluded cases were also sentenced to a longer term in jail than cases included in the final data set. Although the missing data are a limitation to the study, most sentencing research suffers from similar limitations. For example, Harrington and Spohn (2007) were only able to use $59 \%$ of the cases in their original data set. In the current research, $62.4 \%$ of the cases in the original data set were able to be included.

\section{Dependent and Independent Variables}

The present study followed previous research (e.g., Steffensmeier \& Demuth, 2006; Steffensmeier et al., 1993) by examining the in/out decision and the sentence length as two separate decisions, as first done by Holleran and Spohn (2004). The operationalization of the in/out decision, however, deviates from the widely used dichotomized measure where the "in" decision 
Table I. Description of Variables

\begin{tabular}{|c|c|}
\hline Independent Variable & Description \\
\hline \multicolumn{2}{|l|}{ Individual characteristics } \\
\hline Age & In years \\
\hline Race & Black $=1$, White $=0$ \\
\hline Gender & Male $=I$, female $=0$ \\
\hline \multicolumn{2}{|l|}{ Case characteristics } \\
\hline $\begin{array}{l}\text { Prior record variable } \\
\text { ous) }\end{array}$ & 7-category scale $(\mathrm{I}=$ least serious, $7=$ most seri- \\
\hline $\begin{array}{l}\text { Offense variable } \\
\text { ous) }\end{array}$ & 6-category scale ( $\mathrm{I}=$ least serious, $6=$ most seri- \\
\hline Pretrial status & Detained $=1$, not detained $=0$ \\
\hline Type of conviction charge & $\begin{array}{l}\text { Separate dummy variables for property offense, } \\
\text { personal offense, and drug offense; personal } \\
\text { offense is the reference category }\end{array}$ \\
\hline Method of conviction & Trial $=1$, guilty plea $=0$ \\
\hline \multicolumn{2}{|l|}{ Dependent variable } \\
\hline Probation vs. jail vs. prison & Probation $=1$, prison $=2$, jail $=3$ \\
\hline Months in jail & Minimum incarceration sentence in months \\
\hline Months in prison & Minimum incarceration sentence in months \\
\hline
\end{tabular}

includes sentences to either jail or prison and the "out" decision includes sentences of nonconfinement. Instead, this study adopts the trichotomous measure used by Harrington and Spohn (2007), which distinguishes between those sentenced to probation $(n=919)$, jail $(n=404)$, and prison $(n=608)$, with jail left out of the analysis as the reference variable. Table 1 presents a description of each of the independent and dependent variables included in the analyses as well as their coding.

The additional dependent variables examined focused only on those defendants who were sentenced to a term of incarceration. Unlike previous research, the current study examined the length of jail terms and the length of prison terms separately, and $z$ scores were calculated (using Paternoster, Brame, Mazerolle, \& Piquero's, 1998, formula) ${ }^{3}$ to determine whether legal and extralegal variables have different effects for each decision. This allowed for the assessment of any differences in the factors influencing the length of jail and prison terms. Because defendants in Michigan are sentenced to ranges, the minimum sentence of the range was used. The minimum sentence was used because it is more decisive, as all offenders 
must serve their minimum prescribed sentence, as opposed to maximum sentence for which variations exist between offenders, as some serve sentences closer to the maximum than others do.

In each of the models estimated, controls were used for offense severity and prior record. The Michigan Statutory Sentencing Guidelines assigns an offense variable and prior record variable to each offense. ${ }^{4}$ The offense variable ranges from 1 (least serious) to 6 (most serious) (Michigan Judicial Institute, 2007). This offense variable (coded 1-6) was included in the models to control for offense severity. There are seven prior record variables that apply to all offenses and are scored as appropriate in every case. ${ }^{5}$ For each of the seven prior record variables, a numerical score is assigned. The sum of these seven scores determines the offender's prior record level, which ranges from A (least serious) to F (most serious) (Michigan Judicial Institute, 2007). This variable was recoded and included in the models (coded 1-7) to control for prior record.

Several case processing variables were included to control for method of conviction (guilty plea $=0$ or trial $=1$ ), whether the defendant was detained prior to trial (not detained $=0$ or detained $=1$ ), and type of conviction charge. For type of conviction charge, dummy variables were created for each type of offense, either personal, property, or drug. Personal crimes were left out of the model as the reference variable. Offender characteristics for gender $($ female $=0$ or male $=1)$, race $($ White $=0$ or Black $=1)$, and age also were included. ${ }^{6}$

\section{Results}

The individual and case characteristics of the offenders included in the current research are presented in Table 2 . The mean age of the offenders varied by type of sentence, with the mean age of offenders sentenced to probation lower than that of offenders sentenced to jail or prison. The data presented here also indicate that sentences vary by the race and gender of the offender, with White offenders and women sentenced more leniently than Black offenders and men. Not surprisingly, the prior record of the offender as well as the offense variable also affected the sentence; offenders with a more serious prior record and a more severe current offense were more likely to be sentenced to prison. Offenders who were detained prior to trial, those who were convicted through a trial rather than a guilty plea, and those who were convicted of a personal offense were also more likely to be sentenced to prison.

Bivariate correlations computed for each of the independent and dependent variables reveal that none of the variables were highly correlated with each 
Table 2. Descriptive Statistics

\begin{tabular}{|c|c|c|c|c|c|c|}
\hline & \multicolumn{2}{|c|}{$\begin{array}{l}\text { Probation } \\
(n=919)\end{array}$} & \multicolumn{2}{|c|}{$\begin{array}{c}\text { Jail } \\
(n=404)\end{array}$} & \multicolumn{2}{|c|}{$\begin{array}{c}\text { Prison } \\
(n=688)\end{array}$} \\
\hline & $n$ & $\%$ & $n$ & $\%$ & $n$ & $\%$ \\
\hline \multicolumn{7}{|l|}{ Individual characteristics } \\
\hline Age $(M)$ & 29.50 & & 32.40 & & 32.31 & \\
\hline \multicolumn{7}{|l|}{ Race } \\
\hline White & 535 & 52.3 & 162 & 15.9 & 326 & 31.9 \\
\hline Black & 384 & 38.9 & 242 & 25.0 & 362 & 36.6 \\
\hline \multicolumn{7}{|l|}{ Gender } \\
\hline Male & 233 & 18.9 & 360 & 29.2 & 638 & 51.8 \\
\hline Female & 686 & 87.9 & 44 & 5.6 & 50 & 6.4 \\
\hline \multicolumn{7}{|l|}{ Case characteristics } \\
\hline \multicolumn{7}{|l|}{ Prior record } \\
\hline I & 281 & 85.9 & 16 & 4.9 & 30 & 9.3 \\
\hline 2 & 225 & 80.6 & 28 & 10.0 & 26 & 9.3 \\
\hline 3 & 222 & 56.6 & 98 & 24.4 & 76 & 19.2 \\
\hline 4 & 129 & 28.8 & 145 & 32.4 & 174 & 38.8 \\
\hline 5 & 42 & 13.4 & 70 & 22.4 & 201 & 64.2 \\
\hline 6 & 20 & 8.1 & 47 & 19.0 & 181 & 73.0 \\
\hline 7 & 0 & 0 & 0 & 0 & 0 & 0 \\
\hline \multicolumn{7}{|l|}{ Offense Severity } \\
\hline I & 552 & 53.2 & 265 & 25.5 & 221 & 21.3 \\
\hline 2 & 249 & 43.5 & 94 & 16.4 & 230 & 40.1 \\
\hline 3 & 93 & 39.9 & 39 & 16.7 & 101 & 43.4 \\
\hline 4 & 14 & 18.4 & 6 & 7.9 & 56 & 73.7 \\
\hline 5 & 7 & 11.3 & 0 & 0 & 55 & 88.7 \\
\hline 6 & 4 & 13.8 & 0 & 0 & 25 & 86.2 \\
\hline \multicolumn{7}{|l|}{ Pretrial status } \\
\hline Not detained & 823 & 66.4 & 215 & 17.4 & 201 & 16.2 \\
\hline Detained & 96 & 12.4 & 189 & 24.5 & 487 & 63.1 \\
\hline \multicolumn{7}{|c|}{ Type of conviction charge } \\
\hline Property offense & 382 & 56.5 & 126 & 18.6 & 168 & 24.9 \\
\hline Personal offense & 167 & 31.6 & 60 & 11.4 & 301 & 57.0 \\
\hline Drug offense & 286 & 46.9 & 171 & 28.0 & 153 & 25.1 \\
\hline \multicolumn{7}{|l|}{ Method of conviction } \\
\hline Guilty plea & 908 & 46.1 & 399 & 20.3 & 661 & 33.6 \\
\hline Trial & 11 & 25.6 & 5 & 11.6 & 27 & 62.8 \\
\hline Months in jail $(M)$ & & & 5.57 & & & \\
\hline Months in prison $(M)$ & & & & & 35.40 & \\
\hline
\end{tabular}


other. ${ }^{7}$ Tolerance statistics and variance inflation factors were also computed for each of the variables and are displayed in their respective tables. For all models, tolerance statistics exceeded .2 and the variance inflation factors were all below 4 , indicating that all of the variables are independent of each other. Thus, collinearity is not an issue (Mertler \& Vannatta, 2002).

\section{Sentence Type}

The effect of race and gender on sentence type was assessed in three multinomial logistic regression models. The first model examined the effects of race, gender, and age separately. The second model examined the interactions of gender and race. The third model contained interactions for gender, race, and age. In each of the models, jail was left out as the reference category for the dependent variable. Therefore, the results are interpreted as the odds of a defendant receiving probation as opposed to jail and a defendant receiving prison as opposed to jail (the same interpretation was used by Harrington \& Spohn, 2007).

The multinomial logistic regression model presented in Table 3 reveals that the coefficient for race was negative and significant $(b=-0.334, p<$ .05 ), indicating that Black defendants were significantly less likely to receive probation as opposed to jail. The coefficient for race was not significant, however, in the prison model. Therefore, Black defendants were significantly less likely to receive a sentence of probation, as opposed to White defendants, but did not have significantly different odds than Whites of being sentenced to prison as opposed to jail. A similar finding was revealed when examining gender. The coefficient for gender $(b=-0.502, p<.05)$ indicates that women were significantly more likely than men to receive a sentence of probation as opposed to jail. When the prison model is examined, however, the coefficient for gender was not significant. This indicates that women's odds of being sentenced to prison as opposed to jail are not different from men's.

Given the significant effects found for race and gender in the decision to incarcerate a defendant to probation versus jail, predicted probabilities were calculated to determine the effect these factors have on the likelihood of a defendant being sentenced to probation versus jail. The equation used to calculate these probabilities is as follows:

$$
\begin{gathered}
\mathrm{P}(\mathrm{Y}=1)=e\left(a_{0}+b_{1} x_{1}+b_{2} x_{2}+b_{3} x_{3}+\ldots b_{k} x_{k}\right) \\
1+e\left(a 0+b_{1} x_{1}+b_{2} x_{2}+b_{3} x_{3}+\ldots b_{k} x_{k}\right),
\end{gathered}
$$




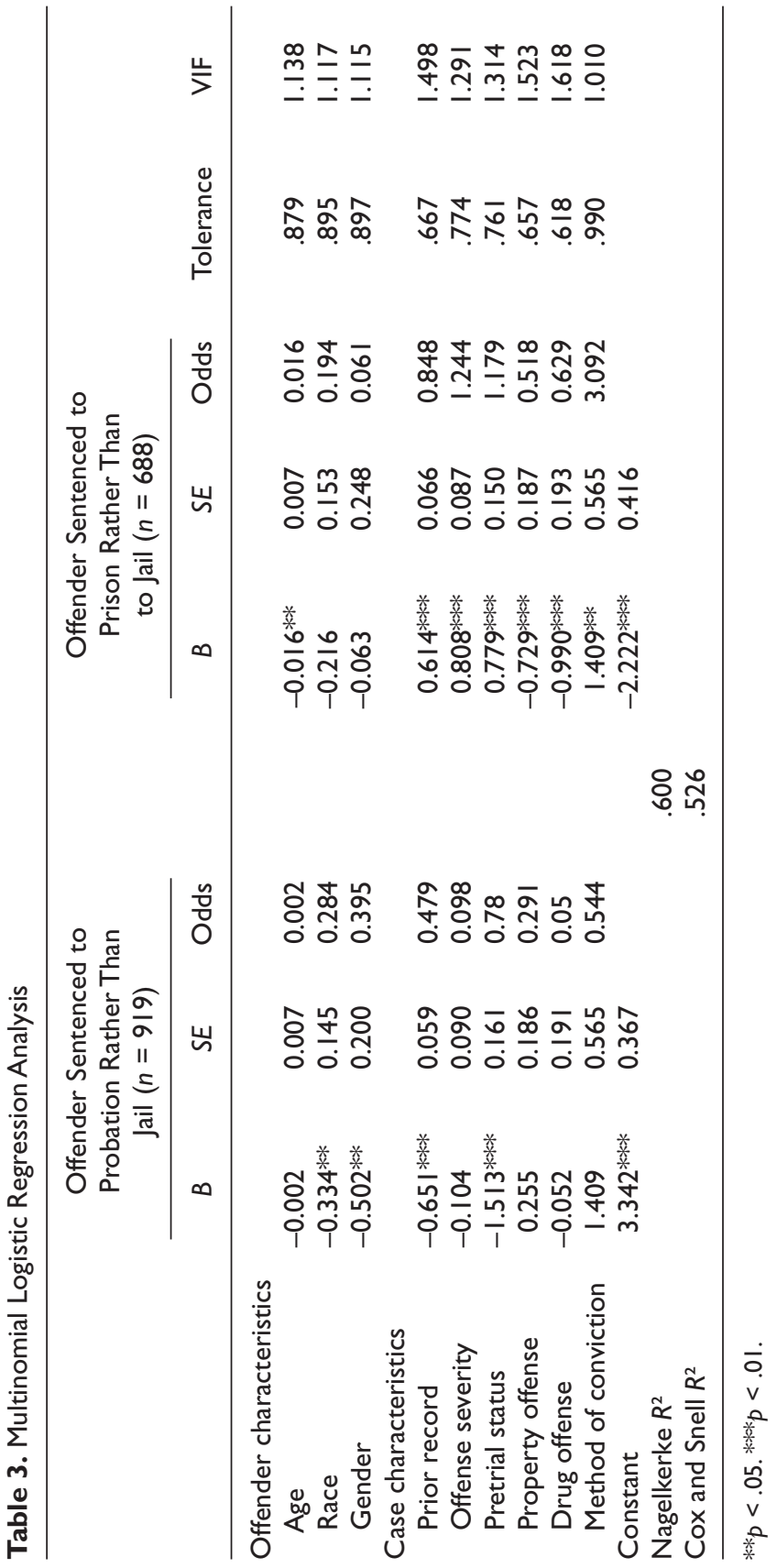


where $a_{0}$ is the constant, $b$ represents each slope estimate, and $x$ is the value of each independent variable (Menard, 2002). With all other independent variables held at their means, the probability of receiving probation for a White defendant was .647 , or $65 \%$, and for a Black defendant, .568, or $57 \%$. This indicates that there was an 8 percentage point difference in the likelihood of receiving probation between a White defendant and a Black defendant. The estimated probability for a female defendant was .704, or $70 \%$, and .590 , or $59 \%$, for a male defendant. This indicates that there was an 11 percentage point difference in the likelihood of receiving probation between men and women.

Age was not significant in the decision between probation and jail. However, past research has found that the effect of age is curvilinear (e.g., Steffensmeier, Kramer, \& Ulmer, 1995; Steffensmeier et al., 1998) with very young (18-20) and older offenders (50 and above) receiving more lenient sentences and those ages 21 to 29 receiving the most severe punishments. To replicate Steffensmeier et al. (1998), the model was reestimated using a quadratic term for age to test whether a curvilinear effect was present. The coefficients for age squared also failed to reach significance ( $b=0.001, p=.208$, probation vs. jail; $b=0.000, p=.846$, prison vs. jail). The impact on the log odds for a 1-unit increase of age was calculated using the following equation:

$$
\exp \left(b_{1}+b_{2}\right) \exp \left(2_{b} 2_{X}\right)
$$

where $b_{1}$ represents the slope of age, $b_{2}$ represents the slope of age squared, and $X$ represents age (DeMaris, 1995). Using this equation, the odds of receiving probation over a sentence of jail for an 18-year-old was 0.987 , 0.993 for a 21 -year-old, 1.001 for a 25 -year-old, 1.011 for a 30 -year-old, 1.031 for a 40 -year-old, 1.052 for a 50 -year-old, and 1.08437 for a 65 -yearold. This indicates that as the age of the defendant increased, the odds of receiving a probation sentence also increased. If a curvilinear effect was present, the coefficients would shift in their direction (e.g., numbers would increase and then decrease and then increase; DeMaris, 1995). Each increase in age resulted in an increased odds (without ever changing direction) of receiving probation; therefore, age did not appear to have a curvilinear effect for this decision point.

Examination of the model also shows that legal variables appear to have a stronger effect on the decision to sentence a defendant to prison as opposed to jail than on the decision to sentence a defendant to probation rather than to jail. In the decision to grant a defendant probation, the only legal variables that had a significant influence were the prior record level $(b=-0.651$, 
$p<.01)$ and whether the defendant was detained prior to trial $(b=-1.513, p$ $<.01)$. In the decision to sentence a defendant to prison, however, all of the legal and process variables examined were significant predictors. As the offense variable $(b=0.808, p<.01)$ increased, a defendant's likelihood of being sentenced to prison increased. The same was found for prior record level $(b=0.614, p<.01)$, with increases in this value resulting in significantly increased likelihood of a defendant being sentenced to prison as opposed to jail. Offense type also was a significant predictor in the decision to sentence a defendant to prison. Drug offenders $(b=-0.990, p<.01)$ and property offenders $(b=-0.729, p<.01)$ had significantly lower odds of being sentenced to prison as opposed to jail than did defendants convicted of a personal crime. Defendants who were detained prior to sentencing also had a significantly greater odds of receiving prison over jail than did those who were not detained $(b=0.779, p<.01)$.

In the decision to sentence a defendant to prison as opposed to jail, the only extralegal variable that reached significance was age. These defendants were less likely to be sentenced to prison than younger defendants (age 18-29). Again, the model was reassessed with a quadratic term, and the equation presented above was used to assess whether nonlinear effects were present. For the decision to sentence a defendant to prison versus jail, the slope for quadratic age was .000 . Given the formula, the impact of age would be $b=0.976$ for all ages (due to the quadratic slope being .000). Because age was significant in the model, however, age was added into the model as three categorical variables (18-29, 30-39, and 40 and over), with the group of youngest offenders left out as the reference category. This model showed that very old offenders, 40 and over $(b=-0.016, p<.01)$, were less likely than young offenders (17-29) to be sent to prison.

Next, the model was estimated with interaction variables included for gender and race. To assess these effects, four dummy variables (Black female, White female, Black male, White male) were created and entered into the original models in place of gender and race. The coefficients are included in Table 4, with Black males left out as the reference category. The results indicate that all of the other defendant groups (White females, $b=$ $0.736, p<.01$; Black females, $b=0.697, p<.05$; and White males, $b=0.399$, $p<.05)$ were more likely to receive probation as opposed to jail than were Black male defendants. In other words, White males, White females, and Black females were all more likely to be sentenced to probation than were Black males. When the model was estimated again with White women as the reference category (full results are available by request from the first author), the only significant difference in the odds of receiving probation was for 


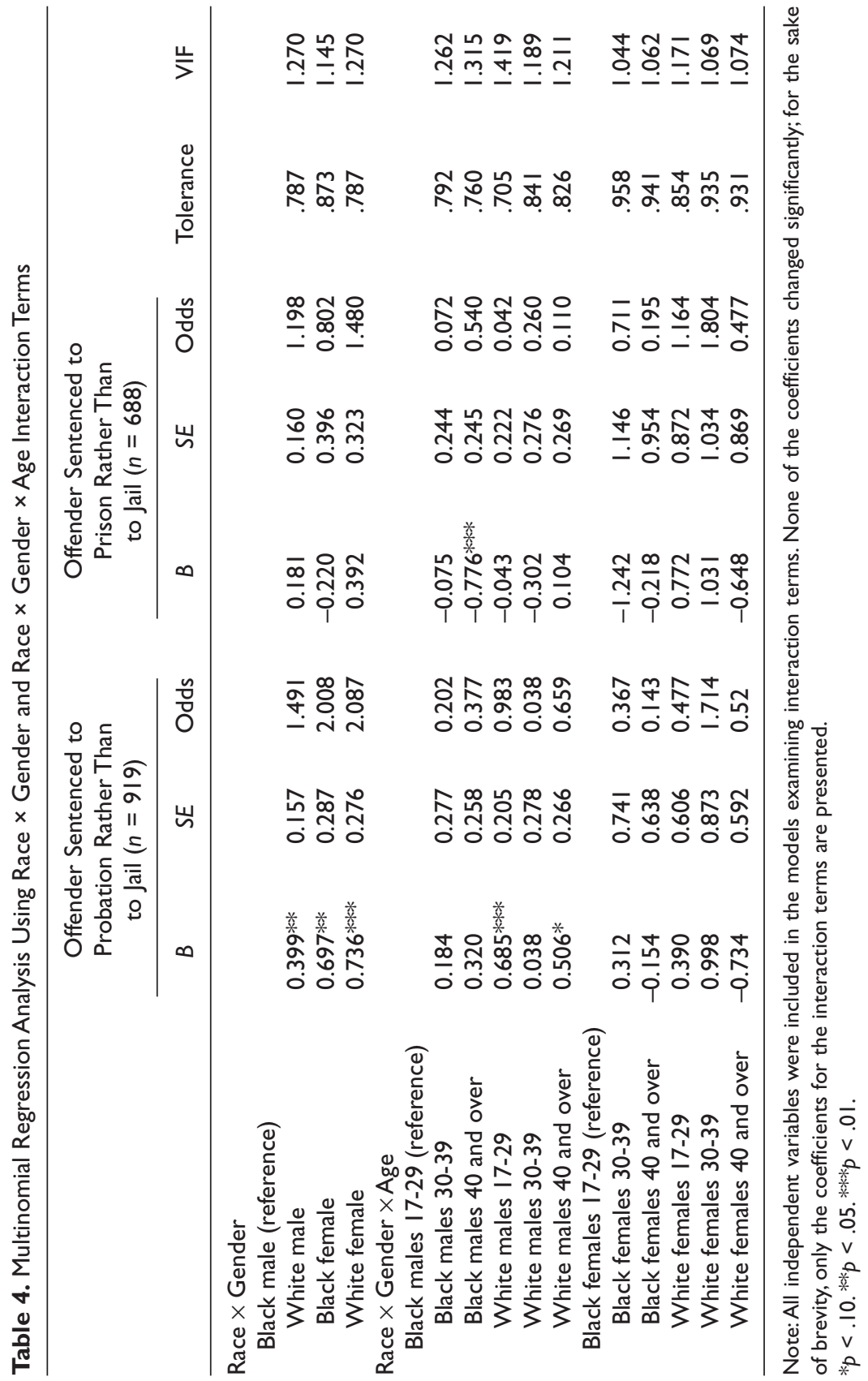


Black males $(b=-0.736, S E=0.276)$, who were significantly less likely than White females to receive probation. The coefficients for Black females $(b=$ $-0.039, S E=0.363)$ and White males $(b=-0.337, S E=0.272)$ were not significant, indicating that they had equal odds of receiving probation as those of White females.

An additional model was estimated to determine if age interacted with race and gender. For this analysis, 12 dummy variables were created to distinguish between age, race, and gender. These results are also presented in Table 4. Similar to the study by Harrington and Spohn (2007), the following measures were used: White females age 17 to $29(n=102)$, White females age 30 to $39(n=37)$, White females 40 and over $(n=51)$, Black females age 17 to $29(n=52)$, Black females age 30 to $39(n=31)$, Black females 40 and over $(n=38)$, White males age 17 to $29(n=435)$, White males age 30 to $39(n=158)$, White males 40 and over $(n=196)$, Black males age 17 to $29(n=454)$, Black males age 30 to $39(n=183)$, and Black males 40 and over $(n=196)$.

Separate models were estimated for men and women. When Black males ages 17 to 29 were left out of the analysis as the reference category, young (age 17-29) White males $(b=0.685, p<.01)$ and older (age 40 and above) White males $(b=0.506 ; p<.10)$ had a significantly higher odds of receiving probation over jail. Therefore, young White males had the least odds of being sentenced to jail rather than to probation. In the prison model, however, only older Black males $(b=-0.776, p<.01)$ had lesser odds of being sent to prison than did young Black males. When the model was reassessed with young White males left out as the reference category (coefficients not shown), the results indicated that only young Black males $(b=-0.596, p<.05)$ and middleage (age 30-39) White males had a significantly lower odds of receiving probation instead of jail. These findings indicate that although Black men were treated more harshly for being young, White men were actually treated more leniently for being young.

When Black females age 17 to 29 were left out of the female model as the reference category, none of the coefficients were significant in either the decision to sentence an offender to probation versus jail or in the decision to sentence an offender to prison versus jail. Therefore, it did not appear that young Black female defendants experienced the same harsh punishment as their male counterparts. To determine whether age was a significant predictor for White females, the model was estimated with young White females left out as the reference category. This analysis showed that older White females $(b=-1.275, S E=0.581, p<.05)$ were significantly less likely to receive a sentence of probation than were young White females. In the decision to 
sentence a defendant to prison as opposed to jail, older White females $(b=-1.281, S E=0.742, p<.10)$ and middle-age Black females $(b=-1.823$, $S E=1.072, p<.10)$ were less likely to be sent to prison than were young White females. Therefore, it appeared that young White women were granted more lenient treatment for their age only in the decision between probation and jail.

\section{Sentence Length}

Four ordinary least squares models for jail sentence length and prison sentence length were examined. The models were first estimated with race and gender entered separately. The models were then estimated with interaction variables for race, gender, and age included. The first model, presented in Table 5, examined the length of the jail term in months a defendant was sentenced. Therefore, only those defendants who received a jail sentence were included $(n=404)$. In the model, the coefficient for gender was significant $(b=1.039, p<.05)$, indicating that men receive jail sentences that are approximately 1 month longer than women's sentences. The coefficients for the offense variable $(b=0.952, p<.01)$, prior record $(b=$ $0.293, p<.05)$, and pretrial release $(b=1.459, p<.01)$ also were positive and significant. As the offense level increased, the length of a defendant's jail sentenced increased by almost 1 month. An increase in a defendant's prior record level only increased the jail term by about 8.7 days. Being detained prior to sentencing resulted in an increase in jail term length of almost $1 \frac{1}{2}$ months. Further examination of the model shows that race and age ${ }^{8}$ did not have a significant influence on the decision of the length of the jail term.

The prison length model (presented in Table 5) included only those defendants who were sentenced to a prison term $(n=688)$. Examination of this model indicates that, similar to the decision to sentence a defendant to prison instead of jail, the decision of the length of a prison term is most strongly influenced by legal variables. Each increase in the offense variable $(b=8.843, p<.01)$ resulted in an almost 9-month increase in a defendant's prison term. Those defendants who were detained prior to sentencing $(b=$ $10.429, p<.01)$ received an increase of more than 10 months to their sentences. Defendants convicted of drug $(b=-16.137, p<.01)$ and property $(b=-19.379, p<.01)$ crimes received significantly shorter sentences than those sentenced to personal crimes. Defendants who were convicted through a trial $(b=52.215, p<.01)$ received sentences that averaged more than 4 years longer than those who pled guilty. This large difference may be due to plea bargains and deals with prosecutors, from which offenders often benefit. 


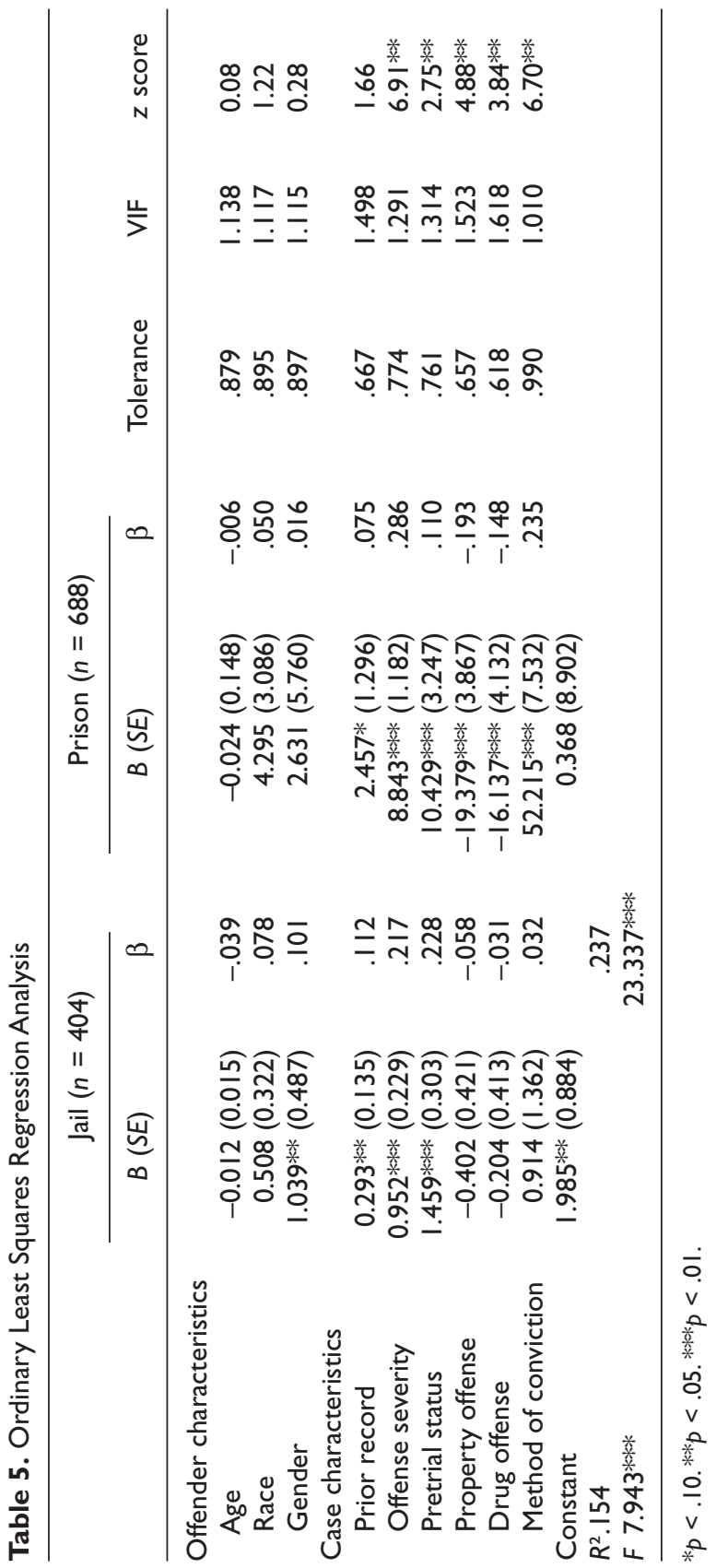


Although jail and prison length were both measured in months, a fair comparison is questionable because a jail sentence can be increased only so much, whereas a prison sentence can be increased with practically no limitation. A 1-month increase in a jail term could be considered much more substantial than a 1-month increase in a prison term. Therefore, it is important to examine the difference in the actual impacts that the variables have on incarceration length. To assess the different impacts that the independent variables had on the incarceration term for jail versus prison, $z$ scores were calculated and are also presented in Table 5. The gender coefficients were significant in the jail length model but not in the prison length model; however, the $z$ score was not significant. Race did not reach significance in either model, nor was the $z$ score significant. This indicates that neither gender nor race had a significantly greater impact on the decision of jail length than on the decision of prison length. Examination of the interactions of the other variables in the model showed that several factors did, however, have varying impacts on the two decisions. The offense variable $(z=6.91)$, crime type (drug $z=3.84$, property $z=4.88$ ), method of conviction $(z=6.70)$, and pretrial release status $(z=2.75)$ all had a larger effect on the prison sentence length decision than on the jail sentence length decision.

When the gender and race interaction variables were added to the models (see Table 6), all groups (White females, $b=-1.277, p<.10$; Black females, $b=-1.416, p<.05$; and White males, $b=-0.591, p<.10)$ received jail sentences that were significantly shorter than those of Black males (reference). Further analysis of the model leaving White females out as the reference category (coefficients not shown) showed no differences between Black females and White males and White females. Therefore, it appeared that only Black males were being sentenced to longer terms in jail. When examining prison length, none of the race and gender interaction variables were significant.

Race and age interaction variables also were assessed for sentence length for men (interactions could not be assessed for women due to the small number of women in each category). This analysis (coefficients shown in Table 6) showed that middle-age Black males $(b=-1.407, p<.05)$ and middle-age White males $(b=-1.459, p<.05)$ received significantly shorter jail sentences than did young Black males (reference). Reanalysis of the model with young White males left out of the analysis (coefficients not shown) showed that none of the other White offender age groups (White older or middle age) were sentenced significantly differently than young White males. Therefore, it appears that age only influenced the sentences of 


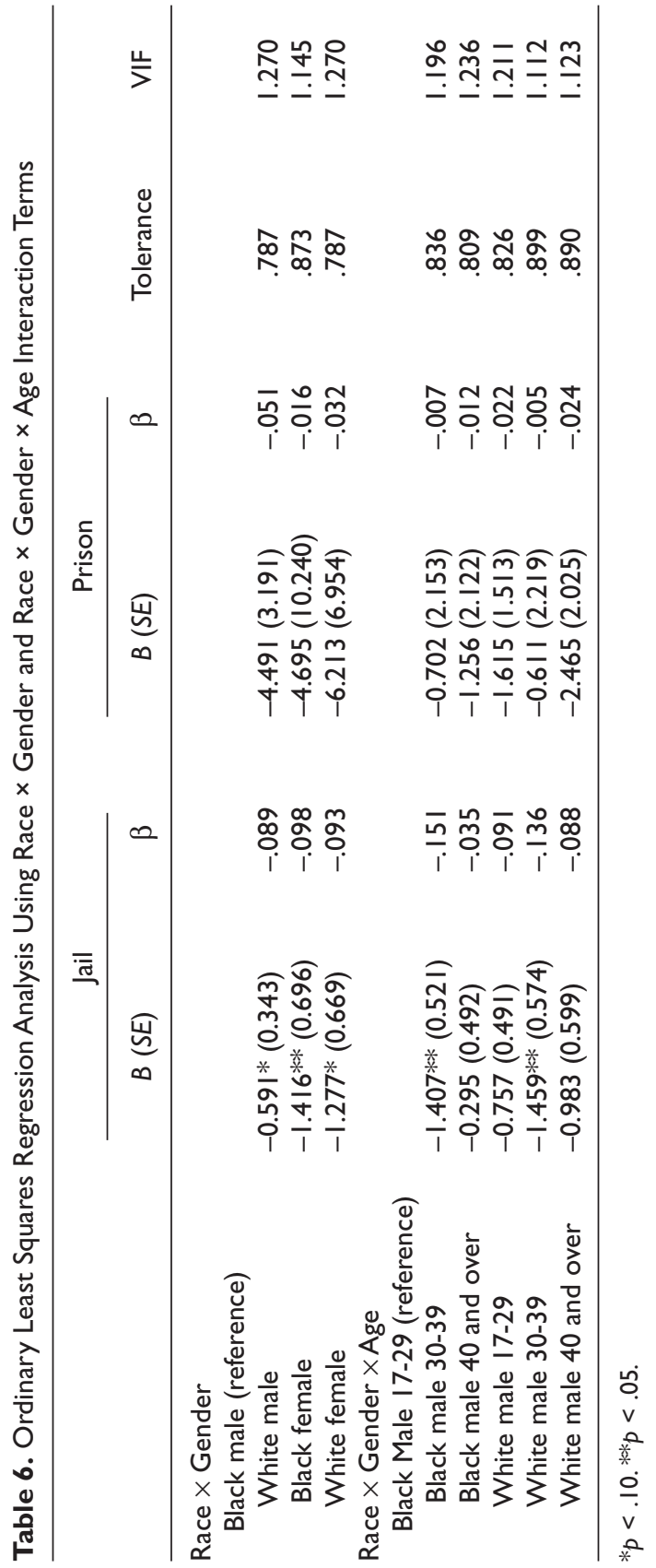


Black males, as jail length did not significantly differ for young, middle-age, or older White males. None of the race, gender, and age interaction variables were significant in the prison length model.

\section{Discussion}

The current study attempted to further the understanding of the effects of race, gender, and age on felony sentences by using a more comprehensive measure of sentencing outcomes. Sentence lengths for jail and prison sentences were examined separately to determine whether legal and extralegal variables have different effects on sentence length to each institution. The results indicated that women were more likely than men to receive a sentence of probation but were equally likely to receive a sentence of prison as opposed to jail, mirroring the results of Harrington and Spohn (2007). When examining race, White defendants were more likely to receive probation as opposed to jail, similar to the findings of Harrington and Spohn. These results differed slightly from those of Harrington and Spohn, however, in the decision between jail and prison. They found that White defendants had greater odds of incarceration in prison as opposed to jail than did Black defendants. The current analysis, however, found no difference between Black and White defendants' odds of receiving a sentence to prison as opposed to jail.

In addition, the results suggest that judges are relying more heavily on legal variables when determining whether to sentence a defendant to prison and when determining the length of the prison term. These findings suggest that judges not only are utilizing extralegal factors more readily when deciding between probation and jail but also are considering legal factors less heavily for jail sentences. Therefore, these results suggest that bias is not found in the decision to sentence a defendant to prison as opposed to jail but is present in the decision to sentence a defendant to probation instead of jail. Although prison is often considered to be a harsher form of punishment than jail, bias in the jail versus probation decision may be equally problematic. The decision to grant a defendant probation keeps offenders in the community and allows them to avoid many of the negative stigmas associated with incarceration. This further allows the defendant to retain a job, familial ties, and community networks.

The results also showed that defendants who were convicted at trial were more likely to be sentenced to prison than to jail and to receive longer prison terms than those who plead guilty. This finding is likely due to defendants who plead guilty receiving plea bargain deals from the prosecutor. It also may be partially due to judges' preference for plea bargains over trials. As 
discussed by Lynch (1994), it is not uncommon for defendants to receive harsher sentences as punishment for their decision to go to trial. This practice, often referred to as a "trial tax," indicates a penalty for making the court go through the process of a trial by not pleading guilty.

When interaction effects of race and gender were examined, the results showed that the significance of race and gender was largely due to Black men being sentenced more harshly than either White men or Black and White women. This is similar to other researchers' previous findings (e.g., Spohn \& Holleran, 2000; Steffensmeier et al., 1998) that Black men are treated more harshly than other groups. The results also indicated, however, that the harsher treatment of Black defendants was only found in the decision to sentence a defendant to probation as opposed to jail.

When possible age interactions were considered, the analysis suggested that being young had different effects for White men and for Black men. Being young for Black men meant harsher treatment, whereas for White men being young meant greater leniency. Therefore, it appears that judges only granted leniency to Black men if they were older and when the decision was whether to send them to prison rather than to jail. For White men, the higher likelihood of receiving probation versus jail indicates that judges may be more likely to give them a second chance and allow them to stay in the community. When the female model was estimated, it suggested that young Black women were not treated more harshly than older Black women. Regardless of age, it appeared that Black women were sentenced similarly. Young White women, on the other hand, were treated more like their White male counterparts and were granted leniency for their age in the decision to sentence them to probation rather than to jail.

These findings can be understood using the logic of Steffensmeier and colleagues' (Steffensmeier et al., 1993; Steffensmeier et al., 1998) focal concerns perspective. The focal concerns perspective suggests that judges base their decisions on the three focal concerns of blameworthiness, protection of the community, and practical constraints and consequences (Steffensmeier et al., 1998). Incorporating Albonetti's (1991) findings that a lack of information available to judges often results in them making decisions based on stereotypes and past experiences, Steffensmeier et al. (1998) asserted that judges sometimes develop a "conceptual shorthand" where they use limited information (e.g., offense seriousness, gender, race) to draw conclusions about the three focal concerns. This theory has been widely used to explain racial and gender disparities in sentencing (e.g., Spohn \& Beichner, 2000; Steffensmeier \& Demuth, 2006; Steffensmeier et al., 1993; Steffensmeier et al., 1998). 
This perspective explains why Black male defendants were found to receive the harshest treatment, as those of minority and male status elicit the strongest perceptions of blame and dangerousness. It is possible that when judges have made the decision to incarcerate and are choosing between incarceration in either jail or prison, legal factors have a much stronger influence on perceptions of dangerousness and there is less need to rely on this conceptual shorthand. Regardless of which decision the judge makes, the defendant will be removed from the community. When judges are deciding between probation and jail, however, there may be more of a reliance on extralegal factors, as the decision involves either taking someone out of the community or leaving that person in the community where he or she might be more likely to reoffend. Therefore, regardless of whether the offense is of great seriousness, those who hold characteristics of perceived dangerousness (Black and male) are removed from the community. Furthermore, women are more likely to sustain community ties (e.g., family) and are viewed as less likely to reoffend than men are (Daly, 1994). White male defendants also are viewed as less criminally involved and less likely than Black males to recidivate (Bridges \& Steen, 1998; Spohn \& Beichner, 2000). These perceptions likely result in women and in White men being considered as better candidates for probation. For White men and for women, being young appears to further reduce perceptions of dangerousness. Being young, on the other hand, is viewed as a negative for Black men and appears to increase negative perceptions.

The results also are largely supportive of Holleran and Spohn's (2004) and Harrington and Spohn's (2007) findings suggesting that more comprehensive measures of the in/out variable need to be employed in sentencing research. When the traditional dichotomous in/out variable ("out" as probation and "in" as a sentence to either jail or prison) was used, race and gender were both found to be significant predictors (coefficients not shown). When the decision of probation, jail, and prison were examined separately, however, the results showed that race and gender had a significant effect only in the decision to sentence a defendant to probation as opposed to jail and not in the decision to sentence a defendant to prison as opposed to jail. It is important to the understanding of sentencing decisions that further research examine the multiple decision options that judges have available to them.

Furthermore, as illustrated in this study, it is possible that judges consider different variables when determining the length of a defendant's jail term than when determining the length of a defendant's prison term. When sentence length for jail and prison were considered in the same model, race and gender did not reach significance. When considered separately, however, women were found to receive significantly shorter jail sentences (but not prison sentences) than their 
male counterparts. The $z$ score comparing the gender for prison length was not significant, however, indicating that gender had a similar impact on both decisions. For the legal and process variables, the $z$ scores were significant, which indicates that they had a greater impact on the prison sentence length decision than on the jail sentence length decision. Considering the results of this study and those done by Spohn and colleagues (Harrington \& Spohn, 2007; Holleran \& Spohn, 2004), more research should be conducted in other sentencing jurisdictions examining gender and racial differences and their interactions using a more comprehensive measure of the in/out and sentence length decisions. Thus, employing more comprehensive measures of the dependent variables may offer insight into explaining why empirical investigations have produced mixed results.

\section{Notes}

1. Michigan implemented indeterminate sentencing guidelines in 1999. The guidelines are applicable to all felony and misdemeanor offenses punishable by more than one year in prison. The indeterminate sentencing structure stipulates that the maximum sentence is established by statute and the minimum sentence is determined by a judge in consultation with the state sentencing guidelines using both the prior record variable and the offense variable. Under the guidelines, the minimum sentence must not exceed two-thirds of the maximum sentence allowable by law. A judge may depart from the appropriate sentence range, but only for a "substantial and compelling reason" which must be recorded (Michigan Judicial Institute, 2007).

2. The data are shown in the following table:

\begin{tabular}{lc}
\hline Independent Variable & Pearson $\chi^{2}$ \\
\hline Age & 67.346 \\
Race & 1.885 \\
Gender & 0.194 \\
Pretrial status & $26.736^{* *}$ \\
Property offense & 0.300 \\
Personal offense & 0.219 \\
Drug offense & 0.018 \\
Method of conviction & $1.762^{* *}$ \\
Probation sentence & $223.872^{* *}$ \\
Jail sentences & $19.527 * *$ \\
Prison sentence & $63.837^{* *}$ \\
Months in jail & $42.582^{* *}$ \\
Months in prison & 27.823 \\
\hline
\end{tabular}

$* * p<.01$. 
3. The formula is

$$
z=\frac{b_{1}-b_{2}}{\sqrt{\left(s e_{1}\right)^{2}+\left(s e_{2}\right)^{2}}}
$$

in which $b_{1}$ is the unstandardized coefficient for Group 1 and $b_{2}$ is the unstandardized coefficient for Group 2. The standard error of the slope for the first group was represented by $\left(s e_{1}\right)$, and $\left(s e_{2}\right)$ was the standard error of the slope for the second group (Paternoster, Brame, Mazerolle, \& Piquero, 1998).

4. There are 19 possible offense variables that can be scored; the sentencing guidelines stipulate which variables will be scored based on the current offense crime group (e.g., crimes against a person, crimes against property, crimes involving a controlled substance). The 19 possible offense variables are aggravated use of a weapon; lethal potential of the weapon possessed; physical injury to a victim; psychological injury to a victim; psychological injury to a member of a victim's family; offender's intent to kill or injure another individual; aggravated physical abuse; victim asportation or captivity; number of victims; exploitation of a vulnerable victim; criminal sexual penetration; contemporaneous felonious acts; continuing pattern of criminal behavior; aggravated controlled substance offenses; property obtained, damaged, lost, or destroyed; degree of negligence exhibited; operator ability affected by alcohol or drugs; threat to the security of a penal institution or court; or interference with the administration of justice.

5. Prior record variables 1 through 5 assign a numerical score for an offender's prior adult felony convictions (distinguishing between high and low severity offenses), prior juvenile felony adjudications (distinguishing between high and low severity offenses), prior misdemeanor adult convictions, and prior misdemeanor juvenile adjudications. Prior record variable 6 assigns a score based on the offender's relationship to the criminal justice system at the time of sentencing for the current offense (i.e., if the offender is a probationer or parolee), and prior record variable 7 assigns a score based on any subsequent or concurrent felony convictions of the offender (i.e., any felony convictions entered after the commission of the current offense).

6. Steffensmeier, Ulmer, and Kramer (1998) also assessed age using five age categories (18-20, 21-29, 30-39, 40-49, and 50 and over). This was replicated but did not produce any significant coefficients (jail: 18-20 reference, 21-29, $b=-0.285$, $p=.199 ; 30-39, b=-0.302, p=.220 ; 40-49, b=-0.374, p=.141$; and 50 and over, $b=-0.111, p=.754$; prison: $18-20$, reference $21-29, b=-0.164, p=.526$; $30-39, b=-0.251, p=.363 ; 40-49, b=-0.474, p=.144$; and 50 and over, $b=$ $-0.601, p=.118)$.

7. A full correlation matrix is available from the first author. 
8. Age also was assessed using categorical variables (18-29, 30-39, and 40 and over), with 18 to 29 left out as the reference category. None of the variables were significant in any of the models (jail length: $30-39, b=-0.129, p=.404$, and 40 and over, $b=-0.128, p=.388$; prison length: $30-39, b=-0.028, p=.984$, and 40 and over $b=-0.993, p=.457$ )

9. All independent variables were included in the models examining interaction terms. None of the coefficients changed significantly; for the sake of brevity, only the coefficients for the interaction terms are presented.

\section{References}

Albonetti, C. A. (1991). An integration of theories to explain judicial discretion. Social Problems, 38, 247-266.

Albonetti, C. A. (1997). Sentencing under the federal sentencing guidelines: Effects of defendant characteristics, guilty pleas and departures on sentencing outcomes for drug offenses, 1991-1992. Law and Society Review, 31, 789-822.

Bickle, G. S., \& Peterson, R. D. (1991). The impact on gender-based family roles on criminal sentencing. Social Problems, 38, 372-394

Bridges, G. S., \& Steen, S. (1998). Racial disparities in official assessment of juvenile offenders: Attributional stereotypes as mediating mechanisms. American Sociological Review, 63, 554-570.

Brennan, P. K. (2006). Sentencing female misdemeanants: An examination of the direct and indirect effects of race/ethnicity. Justice Quarterly, 23, 60-95.

Bushway, S. D., \& Piehl, A. M. (2001). Judging judicial discretion: Legal factors and racial discrimination in sentencing. Law and Society Review, 35, 733-764.

Chiricos, T. G., \& Crawford, C. (1995). Race and imprisonment: A contextual assessment of the evidence. In D. F. Hawkins (Ed.), Ethnicity, race, and crime: Perspectives across time and place (pp. 281-309). Albany: State University of New York Press.

Crawford, C. (2000). Gender, race, and habitual offender sentencing in Florida. Criminology, 38, 263-280.

Crew, B. K. (1991). Sex differences in criminal sentences: Chivalry or patriarchy? Justice Quarterly, 8, 59-83.

Daly, K. (1987). Discrimination in the criminal courts: Family, gender, and the problem of equal treatment. Social Forces, 66(1), 152-175.

Daly, K. (1994). Gender, crime, and punishment. New Haven, CT: Yale University Press.

Daly, K., \& Bordt, R. L. (1995). Sex effects and sentencing: An analysis of the statistical literature. Justice Quarterly, 12, 141-175.

DeMaris, A. (1995). A tutorial in logistic regression. Journal of Marriage and the Family, 57, 956-968. 
Demuth, S., \& Steffensmeier, D. (2004). Ethnicity effects on sentence outcomes in large urban courts: Comparisons among White, Black, and Hispanic defendants. Social Science Quarterly, 85, 994-1011.

Farnworth, M., \& Teske, R. H. C., Jr. (1995). Gender differences in felony court processing: Three hypothesis of disparity. Women and Criminal Justice, 6(2), 23-44.

Harrington, M. P., \& Spohn, C. (2007). Defining sentence type: Further evidence against use of the total incarceration variable. Journal of Research in Crime and Delinquency, 44(1), 36-63.

Holleran, D., \& Spohn, C. (2004). On the use of the total incarceration variable in sentencing research. Criminology, 42, 211-240.

Huang, W. S., Finn, M. A., Ruback, R. B., \& Friedmann, R. R. (1996). Individual and contextual influences on sentence lengths: Examining political conservatism. The Prison Journal, 76, 398-419.

Jeffries, S., Fletcher, G. J. O., \& Newbold, G. (2003). Pathways to sex-based differentiation in criminal court sentencing. Criminology, 41, 329-353.

Kramer, J., \& Steffensmeier, D. (1993). Race and imprisonment decisions. Sociological Quarterly, 34, 357-376.

Lynch, D. (1994). The impropriety of plea agreements: A tale of two counties. Law and Social Inquiry, 19(1), 115-133.

Menard, S. (2002). Applied logistic regression analysis (2nd ed.). Thousand Oaks, CA: Sage.

Mertler, C., \& Vannatta, R. (2002). Advanced and multivariate statistical methods (2nd ed.). Los Angeles: Pyrczak.

Michigan Judicial Institute. (2007). Sentencing guidelines manual. Lansing: Author. Moulds, E. (1980). Chivalry and paternalism: Disparities of treatment in the criminal justice system. Western Political Quarterly, 31, 416-430.

Mustard, D. B. (2001). Racial, ethnic, and gender disparities in sentencing: Evidence from the U.S. Federal Courts. Journal of Law and Economics, 44, 285-313.

Myers, M. A. (2001). Economic inequality and discrimination in sentencing. Social Forces, 65, 746-766.

Nobiling, T., Spohn, C., \& DeLone, M. (1998). A tale of two counties: Unemployment and sentence severity. Justice Quarterly, 15, 459-486.

Orsagh, T. (1985). The judicial response to crime and the criminal: A utilitarian perspective. Journal of Quantitative Criminology, 1, 369-386.

Paternoster, R., Brame, R. Mazerolle, P., \& Piquero, A. (1998). Using the correct statistical test for the quality of regression coefficients. Criminology, 36, 859-866.

Rodriguez, S. F., Curry, T. R., \& Lee, G. (2006). Gender differences in criminal sentencing: Do effects vary across violent, property, and drug offenses. Social Science Quarterly, 87, 318-339. 
Spohn, C., \& Beichner, D. (2000). Is preferential treatment of felony offenders a thing of the past? A multisite study of gender, race, and imprisonment. Criminal Justice Policy Review, 11, 149-184.

Spohn, C., \& Holleran, D. (2000). The imprisonment penalty paid by young unemployed Black and Hispanic male offenders. Criminology, 38, 281-306.

Spohn, C., Welch, S., \& Gruhl, J. (1985). Women defendants in court: The interaction between sex and race in convicting and sentencing. Social Science Quarterly, 66, 178-185.

Steffensmeier, D., \& Demuth, S. (2000). Ethnicity and sentencing in U.S. federal courts: Who is punished more harshly? American Sociological Review, 65, 705729.

Steffensmeier, D., \& Demuth, S. (2006). Does gender modify the effects of race-ethnicity on criminal sanctions? Sentences for male and female, White, Black, and Hispanic defendants. Journal of Quantitative Criminology, 22, 241-261.

Steffensmeier, D., Kramer, J., \& Streifel, C. (1993). Gender and imprisonment decisions. Criminology, 31, 411-446.

Steffensmeier, D., Kramer, J., \& Ulmer, J. (1995). Age differences in sentencing. Justice Quarterly, 12, 584-601.

Steffensmeier, D., Ulmer, J., \& Kramer, J. (1998). The interaction of race, gender, and age in criminal sentencing: The punishment cost of being young, Black, and male. Criminology, 36, 763-797.

Ulmer, J. T., \& Kramer, J. H. (1996). Court communities under sentencing guidelines: Dilemmas of formal rationality and sentencing disparities. Criminology, 34, 383-407.

Zatz, M. S. (2000). The convergence of race, ethnicity, gender, and class in court decision making: Looking toward the 21st century. In Criminal Justice 2000 (Vol. 3, pp. 503-552). Washington, DC: U.S. Department of Justice.

\section{Bios}

Tina L. Freiburger is an assistant professor in the Department of Criminal Justice at the University of Wisconsin-Milwaukee. Her primary research areas are gender and racial disparities in sentencing and women in the criminal justice system.

Carly M. Hilinski is an assistant professor at Grand Valley State University. Her research interests include victimology, particularly crimes against women; assessing the relationships between fear of crime and individual behaviors and attitudes; and crime on the college campus. 